\title{
The association between semantic dementia and surface dyslexia in Japanese
}

\author{
Takao Fushimi ${ }^{a}$, Kenjiro Komori ${ }^{\text {b }}$, Manabu Ikeda ${ }^{\text {b,c }}$, Matthew A. Lambon Ralph ${ }^{d}$, Karalyn Patterson ${ }^{\mathrm{e}, *}$ \\ a Kitasato University, Japan \\ ${ }^{\mathrm{b}}$ Ehime University School of Medicine, Japan \\ ${ }^{c}$ Kumamoto University School of Medicine, Japan \\ d University of Manchester, UK \\ e Medical Research Council, UK
}

\section{A R T I C L E I N F O}

\section{Article history:}

Received 15 October 2008

Received in revised form 19 December 2008

Accepted 23 December 2008

Available online 3 January 2009

\section{Keywords:}

Semantic memory

Cross-language studies

Phonology

Orthography

Reading

\begin{abstract}
A B S T R A C T
One theory about reading suggests that producing the correct pronunciations of written words, particularly less familiar words with an atypical spelling-sound relationship, relies in part on knowledge of the word's meaning. This hypothesis has been supported by reports of surface dyslexia in large case-series studies of English-speaking/reading patients with semantic dementia (SD), but would have increased credibility if it applied to other languages and writing systems as well. The hypothesis predicts that, of the two systems used to write Japanese, SD patients should be unimpaired at oral reading of kana because of its invariant relationship between orthography and phonology. By contrast, oral reading of kanji should be impaired in a graded fashion depending on the consistency characteristics of the kanji target words, with worst performance on words whose component characters take 'minority' (atypical) pronunciations, especially if the words are of lower frequency. Errors in kanji reading should primarily reflect assignment of more typical readings to the component characters in these atypical words. In the largest-ever-reported case series of Japanese patients with semantic dementia, we tested and confirmed this hypothesis.
\end{abstract}

(C) 2008 Elsevier Ltd. All rights reserved.

\section{Introduction}

The processes involved in skilled reading continue to be much debated in the cognitive science and neuroscience literatures. A significant part of this debate concerns the procedures by which readers compute the pronunciations of written words. Copious research, employing a whole range of techniques and populations of both normal and abnormal readers, has established that the translation from orthography to phonology $(\mathrm{O} \rightarrow \mathrm{P})$ occurs with reference both to generalised knowledge of sub-word $\mathrm{O} \rightarrow$ P correspondences and to word-specific information (e.g. Coltheart, Rastle, Perry, Langdon, \& Ziegler, 2001; Dilkina, McClelland, \& Plaut, 2008; Plaut, McClelland, Seidenberg, \& Patterson, 1996). There are differing views, however, about the precise nature of both of these forms of knowledge. One of the major differences between various models of reading is their stance with regard to the following question: is word meaning a significant component of the word-specific information that contributes to accurate pronunciation of written words?

\footnotetext{
* Corresponding author at: MRC Cognition \& Brain Sciences Unit, 15 Chaucer Road, Cambridge CB2 7EF, UK. Tel.: +44 1223 273725; fax: +44 1223359062.

E-mail address: karalyn.patterson@mrc-cbu.cam.ac.uk (K. Patterson).
}

One neuropsychological form of evidence germane to this question concerns the oral reading performance of patients with impaired knowledge of word meanings. Of course, such evidence is only useful if there are patients with semantic deficits but no additional major problems that might affect their reading, such as a letter identification deficit or a phonological impairment. Fortunately for this aspect of reading research, there is an appropriate set of patients: those with semantic dementia(SD) whose degenerative brain disease causes a relatively selective deterioration in semantic memory (Snowden, Goulding, \& Neary, 1989; Warrington, 1975). The semantic deficit in SD is not confined to words: it affects central conceptual knowledge however this is accessed (by words, pictures, objects, non-verbal sounds, etc.: Adlam et al., 2006; Bozeat, Lambon Ralph, Patterson, Garrard, \& Hodges, 2000; Lambon Ralph \& Howard, 2000). But the disease usually does not, at least until late in progression, afflict any of the obvious or putative components of oral reading other than word meaning. So, can SD patients read aloud accurately?

Before we begin to answer this question, a little more background will be useful, because the answer might be determined in part by the characteristics of the language that the patients speak and read. One of the main factors that vary across different languages and writing systems is the degree to which a word's pronunciation can be deduced from its orthographic structure. In English, the $\mathrm{O} \rightarrow$ P relationship is quasi-regular, meaning that "the 
relationship between inputs and outputs is systematic but admits many exceptions" (Plaut et al., 1996, p. 56). For example, the English words new, few, stew, crew, flew, etc. have a systematic relationship between orthographic pattern and pronunciation, but their atypical neighbour sew is an exception. Furthermore, as emphasised by Shallice, Warrington, and McCarthy (1983), this quasi-regular $\mathrm{O} \rightarrow \mathrm{P}$ relationship in English is not a dichotomy: the atypicality of the exceptions is graded rather than absolute.

To begin with, then, let us take the more specific question of whether English-speaking SD patients read aloud accurately. The answer to this question is both yes and no, in two senses. The first yes-and-no applies to the prevalent pattern of reading performance in SD patients who speak and read English. Yes, the patients do well in oral reading of words characterised either by typical $\mathrm{O} \rightarrow \mathrm{P}$ correspondences or by high word frequency, and especially for words with both of these advantages. As $\mathrm{O} \rightarrow \mathrm{P}$ typicality declines, especially for less common words, then the answer is no, because here the patients' word-reading accuracy is substantially below normal. The reading disorder characterised by a relatively selective deficit on $\mathrm{O} \rightarrow \mathrm{P}$ atypical words is known as surface dyslexia (Marshall \& Newcombe, 1973).

The second yes-and-no applies if one considers not just the prevalent pattern of performance but the range across all of the English-speaking SD patients whose reading ability has been reported. Of those cases tested on appropriate word sets varying in frequency and typicality, a few have been unimpaired even for low-frequency atypical words (Blazely, Coltheart, \& Casey, 2005; Cipolotti \& Warrington, 1995). These apparent counter-examples can be understood if both disease stage and individual differences are taken into account. Woollams, Lambon Ralph, Plaut, and Patterson (2007) reported reading performance in 51 cases of SD, with about half of them tested longitudinally: 48 of the 51 patients were surface dyslexic readers on first assessment; of the three who were not, all became surface dyslexic with further semantic deterioration. Woollams et al. referred to this (eventually) universal pattern of Surface Dyslexia in Semantic Dementia as "SD-Squared". Dilkina et al. (2008) produced a computational model of semantics and reading in which manipulations of individual differences resulted in successful simulation of the very common SD-Squared pattern but also the occasional observation of preserved reading in SD.

As always in this sort of evidence, the nature of the errors can be as informative as the accuracy scores. The great majority of SD patients' incorrect reading responses occur to $\mathrm{O} \rightarrow$ P atypical words; and in the great majority of these errors, the patients read the atypical word as if it were typical (Patterson et al., 2006; Woollams et al., 2007). Thus the usual error to sew is "sue", to steak is "steek", to gauge is "gawdge" and so on.

Most research on reading, whether normal or impaired, has been conducted in languages with an alphabetic writing system, especially (though of course not exclusively) English. An added layer of interest and complexity is introduced when considering that not all alphabetic writing systems have the $\mathrm{O} \rightarrow \mathrm{P}$ characteristics of English, and further that not all writing systems are alphabetic. Japanese provides a particularly informative 'case study', both on its own and when contrasted with English. Two different forms of orthography, neither of them alphabetic, are required to write any sentence in Japanese. Morphographic kanji, derived originally from Chinese characters, is used to write most nouns and the stems of verbs and adjectives. Syllabic (or more accurately, moraic) kana, specifically hiragana, is used to write function words and the obligatory inflections on verbs and adjectives. Loan words and words warranting emphasis are usually rendered in a parallel form of kana, called katakana. The two Japanese writing systems, kanji and kana, are especially research-relevant because of their positions on the continuum of $\mathrm{O} \rightarrow \mathrm{P}$ predictability.
Kana is not quasi-regular, it is simply regular. Each kana character corresponds in a perfectly predictable fashion to a single mora of spoken Japanese. A mora is the time-based phonological unit of spoken Japanese, mostly either a vowel on its own, like/a/, or a consonant + vowel combination like/ka/. The important point here is that the hiragana symbol $\varpi$ is always pronounced/a/and the hiragana symbol $\nrightarrow$ is always pronounced/ka/, independent of context. The symbols for each mora in katakana are different but the same invariance of $\mathrm{O} \rightarrow \mathrm{P}$ applies.

Kanji is not only quasi-regular, it is less systematic than English. About two-thirds of the kanji characters used in everyday Japanese writing/reading have two or more different pronunciations, and the pronunciation appropriate for a given word depends upon the other component character(s). Furthermore, the two or more pronunciations may have no similarity whatsoever. For example, the two-character kanji word 神経 is pronounced/shi$\mathrm{N}$-ke-i/and means nerve or neuron. Its first character 神, which is pronounced/shi-N/in this word, is pronounced/ka-mi/in other words: not a single phoneme in common between the two. This might begin to sound as if there is no $\mathrm{O} \rightarrow \mathrm{P}$ systematicity at all in kanji, but that is not true. Kanji is quasi-regular, for two reasons: (a) about one-third of kanji characters have only a single pronunciation each; (b) for the characters with multiple pronunciations, there is often a 'dominant' pronunciation that is appropriate to a (variablesized) majority of the words in which the character appears. A precise characterisation of the typicality of pronunciation for kanji words requires a very graded scale; but for convenience, a simplified 3-way classification serves well (Fushimi, Ijuin, Patterson, \& Tatsumi, 1999; Fushimi et al., 2003). A given kanji word can be called consistent if each of its component characters is associated with only one pronunciation. It can be labelled inconsistent-typical if each component character has more than one possible pronunciation but, across all words containing these characters, the correct pronunciation of all characters in the target word is the most common. And it can be described as inconsistent-atypical if each component character has more than one possible pronunciation and the correct pronunciation of each character in the target word is in the minority across the set of words in which those characters occur. In the stimulus set used here (from Fushimi et al., 1999), all consistent words were composed of two consistent characters; all inconsistent-typical words consisted of two inconsistent-typical characters; and the majority of inconsistent-atypical words had two inconsistent-atypical characters, with a few where one character was inconsistent-atypical and one was inconsistent-typical.

Kanji differs from an alphabetic writing system like English not only in the degree of $\mathrm{O} \rightarrow$ P systematicity, but also in the relationship between orthography and semantics $(\mathrm{O} \rightarrow \mathrm{S})$. In English, segments of words on their own reveal little about whole-word meaning (for example, the semantics of cabinet have nothing to do with cab, bin or net), and single letters typically convey no semantic information. In contrast, individual kanji characters always have meaning, although the meaning of the single character is not always transparently related to the meaning of a multi-component word containing that character. For example, as mentioned above, the two-character kanji word 神経, , pronounced/shi-N-ke-i/, means nerve or neuron; but the first character of this word on its own, pronounced/ka$\mathrm{mi} /$, means god. The meaningfulness of each component of a kanji word might influence the process or ease with which skilled readers extract meaning from written words; but with regard to reading aloud, the question of whether word meaning enters into the $\mathrm{O} \rightarrow \mathrm{P}$ computation is just as salient in kanji as in English. And once again, evidence from SD is pertinent.

As described above, English SD cases almost invariably show major effects of both word frequency and $\mathrm{O} \rightarrow \mathrm{P}$ predictability, and an interaction between these two main effects, on reading accuracy. If this pattern generalises to other languages and 
writing systems, what predictions can be made about oral reading success in Japanese SD? Given that the $\mathrm{O} \rightarrow \mathrm{P}$ relationship in kana is perfectly systematic, one would expect Japanese SD patients to exhibit more-or-less flawless oral reading in kana. For kanji, the prediction is impaired reading modulated by word frequency and interacting with the 3-way classification of $\mathrm{O} \rightarrow \mathrm{P}$ predictability described above: best success for consistent kanji words, intermediate for inconsistent-typical and lowest scores for inconsistent-atypical words. Furthermore, when the patients make errors in reading kanji words, they should mainly produce typical pronunciations of the characters in atypical words.

Available evidence about single-word oral reading performance by Japanese SD patients is in line with these predictions; but apart from some anecdotal observations, only four published cases of SD in Japan have included an experimental evaluation of reading: one case in Patterson, Suzuki, Wydell, and Sasanuma (1995), one in Fushimi et al. (2003) and two in Nakamura, Nakanishi, Hamanaka, Nakaaki, and Yoshida (2000). For at least two different reasons, it seemed valuable to investigate reading performance in a larger sample of Japanese-speaking SD patients. First, single-case studies sometimes produce results that are unrepresentative of the impact of a particular neurodegenerative disease or brain lesion on some cognitive ability, and a case series can thus provide more solid and generalisable conclusions; one is asking not "what is the reading performance of this Japanese SD patient?" but "does SD have a consistent impact on reading in Japanese?" Secondly, a case series with varying degrees of severity allows one to observe the characteristics of performance across its range. That is, not "how does this particular degree of semantic degradation affect this patient's reading?", but "what is the pattern of reading skill across a set of patients with different degrees of semantic deterioration?"

\section{Methods}

\subsection{Participants}

Ten patients from the Higher Brain Function Clinic of the Department of Neuropsychiatry at Ehime University Hospital participated in this study; all conformed to published criteria for SD (Hodges, Patterson, Oxbury, \& Funnell, 1992; Neary et al., 1998). Structural magnetic resonance imaging in all cases revealed atrophy of both anterior/inferior temporal lobes; nine of the ten patients had the more common SD asymmetry of greater left- than right-sided degeneration and one case (MN) had the reverse. The research was conducted with the understanding and the consent of each patient, and was approved by the Ethical Committee of the Ehime University School of Medicine.

No specific control group was tested for this study: normal reading data are available from a study by Fushimi et al. (1999) for which the stimulus materials used here were designed. These control data are from normal individuals much younger than the patients (average age of patients $=66$ and of controls $=30$ ) but should not over-estimate what would be normal reading accuracy for people of the patients' age, for two reasons. First of all, the younger controls, for whom Fushimi et al. (1999) were measuring response times as well as accuracy, responded to the kanji words under time pressure (that is, they were asked to read each word aloud as quickly as possible after it appeared on the computer screen), whereas the patients had no time constraints. Secondly, although spoken Japanese vocabulary (like that of most languages used by a large population) has either remained fairly constant or increased somewhat over recent decades, it is generally agreed that knowledge of kanji written-word vocabulary is on the decline. Therefore, if anything, the younger controls were probably less rather than more likely than the patients (pre-morbidly) to know some of the lower-familiarity kanji stimulus words.

All of the patients were receiving longitudinal assessment at the clinic in Ehime. The kanji reading test that forms the main part of this study plus the other relevant assessments were administered to seven of the ten cases at a single time-point in their longitudinal evaluation. Of the remaining three cases, two received the reading and other relevant tests at two different time points, and one patient was tested on three occasions. The study thus consists of 10 different patients but 14 different assessments of reading germane to the purpose of the study. For the patients with two or three sets of observations, the tests were repeated at a gap of 1-3 years.

Table 1 provides demographic details for all of the cases, along with scores on standardised cognitive assessments; Tables 2 and 3 give performance on some background neuropsychological testing (see description below). In all of these tables, patients are ordered in the following fashion: (a) the three patients with more than one testing round are listed first, with scores for their three (in the case of $\mathrm{TI}$ ) or two (for SK and TMO) rounds in succession so that changes over time can be easily observed; the remaining seven patients who only had one testing round each are listed in descending order of MMSE score.

\subsection{Test materials and results: background}

The tests in Table 1 are standard assessments of general cognitive function: MMSE (Mini Mental Status Examination), CDR (Clinical Dementia Rating), RCPM (Raven's Coloured Progressive Matrices) and Digit-Span Forwards and Back. The tests in Tables 2 and 3 are a subset of those standardly used in the Higher Brain Function Clinic at Ehime University Hospital. Measures not involving semantic memory or language in Table 2 include the Rey Complex Figure (Copy and Recall) and Calculation. Assessments of language and semantics in Table 2 include Word Repetition; Mora Fluency (the approximate equivalent of letter fluency in western languages); Category Fluency; Object Naming from line drawings of common everyday objects; and Word-Picture Matching with spoken word targets and 10 line-drawing choices: the target plus nine within-category distractors. The naming and word-picture matching tests, which use the same 90 items, are very easy: scores even a little off maximum are abnormal. The same is true for the tests in Table 3, which come from the SLTA (the Japanese Standard Language Test for Aphasia: SLTA Committee, 1997).

The profile of this patient population conveyed by Tables $1-3$ is, on the whole, completely characteristic of semantic dementia as it has been described in the literature over the last few decades (see for example Hodges et al., 1992; Snowden, Neary, \& Mann, 1996). The patients mostly had reasonably well preserved performance on tests that do not call on semantic memory, including RCPM, Digit Span, Rey Figure, Calculation, Word Repetition. They were all perfect in kana oral reading, both single characters and words. By contrast, performance on the majority of the expressive and receptive language and semantic memory tests (apart from a few of the very easy tests like the word-picture matching subtest of the SLTA) was abnormal in every case. There are a few apparent oddities, particularly regarding category fluency: several of the patients had better performance in category than letter fluency, whereas the usual pattern in SD is the other way round (Hodges \& Patterson, 1996); and TMO's success in category fluency increased rather than declining over the 2 years between his first and second testing rounds. The explanation for these findings is that SD patients attending the Higher Brain Function Clinic in Ehime engage in frequent (often daily) practice on the 90 -item tests of naming and word-picture matching, and are often able to use their increased ease of producing these particular object names in the category-fluency test. In fact, if names that form part of the practised tests were to be subtracted from the category fluency measure, many of these fluency scores would be zero.

\subsection{Test materials: experiment}

Experimental stimuli comprised 120 two-character kanji words, with 20 words in each of the six conditions formed by crossing three bands of consistency with two bands of word frequency. Consistency was classified with reference to a target word's orthographic neighbourhood, identified as all the words that share the same character at the same position in the corpus of approximately 31,000 twokanji character words listed in a standard Japanese dictionary (Nishio, Iwabuchi, \& Mizutani, 1986). Consistency can be captured by the measure 'friends'/neighbours: that is, the number of items in a target word's neighbourhood for which the pronunciation of the component character is the same, divided by all items in the orthographic neighbourhood (Fushimi et al., 1999). As already briefly described above, this stimulus set classified target words into three consistency conditions: consistent words were those whose constituent characters have the identical pronunciation across all neighbours; the component characters of inconsistent-typical words have more than one pronunciation across the neighbourhood but the appropriate pronunciation of each character in the target word is statistically the most typical; inconsistent-atypical words have characters with more than one pronunciation and the appropriate one in the case of each component character is not the most typical. For all words in the first two conditions and almost all in the third condition, both characters had the same consistency status, making the three types an appropriate description of the whole word. Table 4 provides information about the characteristics of the words in each of the six conditions with respect to length, frequency, familiarity, character frequency and the friends/neighbours measure.

\subsection{Procedure}

Each patient was asked to read the set of 120 kanji words on the occasion of a normal visit for longitudinal assessment at the Higher Brain Function Clinic at Ehime University Hospital. Reading aloud appears to be a virtually self-explanatory task: almost all patients, even those with severe comprehension impairment, seem to find it natural to read aloud a printed word when it is placed in front of them. The 120 words were presented on a computer screen, one at a time, with words from the six conditions in randomised order. There was no time pressure: the experimenter initiated trial $N+1$ when the patient had responded to trial $N$. The patients' responses were scored 'on-line' by the experimenter and also audio-recorded for later checking of errors.

In order to include all of the data in the simple descriptive analyses of reading accuracy and error types, each observation was treated as independent: that is, 
Table 1

Demographic information and results of standard cognitive assessments.

\begin{tabular}{|c|c|c|c|c|c|c|c|c|}
\hline Patient & Sex & Age & Years of education & Duration (years) & MMSE (30) & CDR & RCPM (36) & Digit span F/B \\
\hline TI-1 & M & 57 & 16 & 3 & 28 & 0.5 & 35 & $6 / 5$ \\
\hline TI-2 & & 60 & & 6 & 20 & 1 & 35 & $6 / 5$ \\
\hline TI-3 & & 62 & & 8 & 7 & 2 & 34 & NT \\
\hline SK-1 & M & 58 & 16 & 2 & 23 & 0.5 & 33 & $7 / 5$ \\
\hline SK-2 & & 59 & & 3 & 27 & 0.5 & 36 & $7 / 5$ \\
\hline TMO-1 & M & 54 & 12 & 2 & 27 & 0.5 & 35 & $6 / 4$ \\
\hline TMO-2 & & 56 & & 4 & 23 & 1 & 36 & $5 / 4$ \\
\hline YI & M & 57 & 12 & 1 & 28 & 0.5 & 29 & $3 / 4$ \\
\hline TAM & M & 78 & 15 & 1 & 28 & 0.5 & 31 & $5 / 4$ \\
\hline $\mathrm{MN}$ & $\mathrm{F}$ & 64 & 12 & 2 & 26 & 0.5 & 29 & $6 / 6$ \\
\hline ST & M & 76 & 9 & 3 & 25 & 0.5 & 34 & $6 / 4$ \\
\hline MO & $\mathrm{F}$ & 82 & 10 & 4 & 16 & 1 & 33 & $6 / 4$ \\
\hline $\mathrm{CHN}$ & $\mathrm{F}$ & 82 & 8 & 4 & 12 & 0.5 & 26 & $5 / 3$ \\
\hline MT & $\mathrm{F}$ & 58 & 9 & 5 & 6 & 2 & 28 & $4 / 3$ \\
\hline
\end{tabular}

Table 2

Results of background neuropsychological testing. Note: n.t. = not tested.

\begin{tabular}{|c|c|c|c|c|c|c|c|c|c|}
\hline Patient & $\begin{array}{l}\text { Rey copy } \\
(36)\end{array}$ & $\begin{array}{l}\text { Rey recall } \\
(36)\end{array}$ & $\begin{array}{l}\text { Calculation } \\
(20)\end{array}$ & $\begin{array}{l}\text { Word } \\
\text { repet'n (10) }\end{array}$ & $\begin{array}{l}\text { Kana reading } \\
(10)\end{array}$ & $\begin{array}{l}\text { Letter (mora) } \\
\text { fluency }\end{array}$ & $\begin{array}{l}\text { Categ. } \\
\text { fluency }\end{array}$ & $\begin{array}{l}\text { Object } \\
\text { naming (90) }\end{array}$ & $\begin{array}{l}\text { Word-picture } \\
(90)\end{array}$ \\
\hline TI-1 & 36 & 13.5 & 19 & 10 & 10 & 5 & 14 & 29 & 73 \\
\hline TI-2 & 33 & 19 & 14 & 10 & 10 & 5 & 5 & n.t. & n.t. \\
\hline TI-3 & 35 & n.t. & 8 & 10 & 10 & n.t. & n.t. & n.t. & n.t. \\
\hline SK-1 & 35 & 13.5 & 20 & 10 & 10 & 21 & 23 & 53 & 77 \\
\hline SK-2 & 36 & 22 & 18 & 10 & 10 & 11 & 18 & n.t. & n.t. \\
\hline TMO-1 & 35 & 18 & 18 & 10 & 10 & 16 & 11 & 29 & 74 \\
\hline TMO-2 & 36 & 33 & 18 & 10 & 10 & 10 & 40 & n.t. & n.t. \\
\hline YI & n.t. & n.t. & 20 & 10 & 10 & 5 & 28 & 49 & 78 \\
\hline TAM & 31 & 17.5 & 15 & 10 & 10 & 16 & 13 & 64 & 80 \\
\hline MN & n.t. & n.t. & 20 & 10 & 10 & 10 & 16 & 45 & 63 \\
\hline ST & n.t. & n.t. & 10 & 10 & 10 & 0 & 12 & 33 & 65 \\
\hline MO & n.t. & n.t. & 18 & 10 & 10 & 5 & 7 & 27 & 37 \\
\hline $\mathrm{CHN}$ & 32 & 3 & 14 & 10 & 10 & 1 & 2 & 29 & 68 \\
\hline MT & 32 & n.t. & 18 & 10 & 10 & 1 & 0 & 16 & 28 \\
\hline
\end{tabular}

Table 3

Results for each patient on SLTA subtests involving semantics but not written words.

\begin{tabular}{|c|c|c|c|c|c|c|c|}
\hline Patient & $\begin{array}{l}\text { Spoken word-picture } \\
\text { match (10) }\end{array}$ & $\begin{array}{l}\text { Spoken sentence } \\
\text { compreh'n (10) }\end{array}$ & $\begin{array}{l}\text { Spoken command } \\
\text { compreh'n (10) }\end{array}$ & $\begin{array}{l}\text { Picture naming } \\
\text { objects (20) }\end{array}$ & $\begin{array}{l}\text { Picture naming } \\
\text { actions (10) }\end{array}$ & $\begin{array}{l}\text { Spoken scene } \\
\text { description (6) }\end{array}$ & $\begin{array}{l}\text { Word fluency } \\
\text { animals }\end{array}$ \\
\hline TI-1 & 10 & 7 & 3 & 5 & 7 & 4 & 0 \\
\hline TI-2 & 9 & 5 & 1 & 3 & 5 & 5 & 0 \\
\hline TI-3 & 6 & 0 & 0 & 1 & 0 & 3 & 0 \\
\hline SK-1 & 10 & 9 & 5 & 9 & 9 & 4 & 13 \\
\hline SK-2 & 10 & 10 & 3 & 7 & 9 & 5 & 6 \\
\hline TMO-1 & 9 & 10 & 5 & 9 & 7 & 5 & 2 \\
\hline TMO-2 & 9 & 9 & 2 & 8 & 5 & 5 & 10 \\
\hline YI & 9 & 8 & 4 & 10 & 8 & 3 & 8 \\
\hline TAM & 10 & 8 & 6 & 14 & 7 & 5 & 6 \\
\hline MN & 10 & 7 & 4 & 7 & 7 & 4 & 2 \\
\hline ST & 10 & 9 & 6 & 13 & 8 & 5 & 3 \\
\hline MO & 10 & 8 & 0 & 7 & 6 & 4 & 0 \\
\hline $\mathrm{CHN}$ & 10 & 7 & 5 & 5 & 5 & 5 & 0 \\
\hline MT & 7 & 6 & 0 & 2 & 4 & 4 & 0 \\
\hline
\end{tabular}

\section{Table 4}

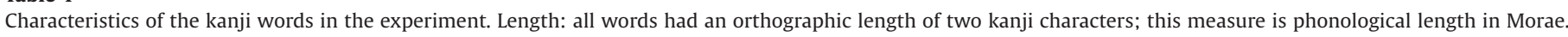

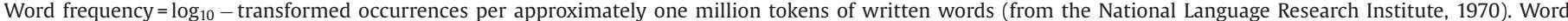

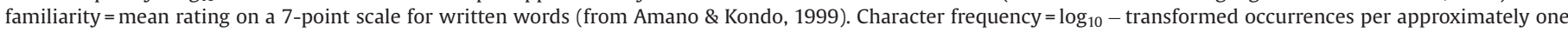

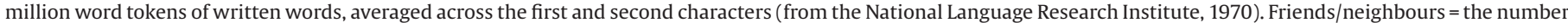
of items in a target word's orthographic neighbourhood for which the pronunciation of the component character is the same, divided by all items in the neighbourhood.

\begin{tabular}{|c|c|c|c|c|c|c|}
\hline & Hi-freq. consistent & Hi-freq. typical & Hi-freq. atypical & Lo-freq. consistent & Lo-freq. typical & Lo-freq. atypical \\
\hline Length (Morae) & $3.55(0.51)$ & $3.65(0.49)$ & $3.45(0.51)$ & $3.55(0.51)$ & $3.40(0.50)$ & $3.50(0.51)$ \\
\hline Word frequency & $1.77(0.23)$ & $1.84(0.23)$ & $1.72(0.22)$ & $0.76(0.06)$ & $0.77(0.06)$ & $0.78(0.06)$ \\
\hline Word familiarity & $6.12(0.31)$ & $6.01(0.36)$ & $6.02(0.47)$ & $5.38(0.57)$ & $5.48(0.49)$ & $5.44(0.60)$ \\
\hline Character frequency & $2.71(0.27)$ & $2.77(0.23)$ & $2.78(0.31)$ & $2.61(0.31)$ & $2.52(0.32)$ & $2.46(0.45)$ \\
\hline Friends/neighbours & $1.00(0.00)$ & $0.74(0.07)$ & $0.42(0.13)$ & $1.00(0.00)$ & $0.71(0.07)$ & $0.33(0.15)$ \\
\hline
\end{tabular}




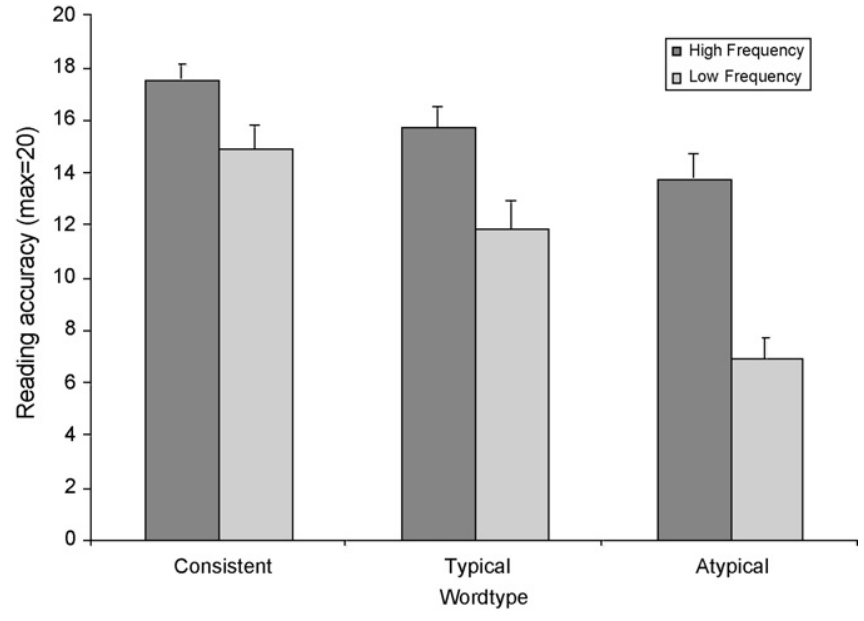

Fig. 1. Average number of correct responses for each of the six conditions across the 14 sets of patient reading data.

results for SK and TMO on the second testing round and for TI on the second and third testing rounds were considered in the same fashion as observations from a different patient. This seems justified on the basis of the progressive nature of semantic dementia (Lambon Ralph, McClelland, Patterson, Galton, \& Hodges, 2001; Woollams, Cooper-Pye, Hodges, \& Patterson, 2008). For the subsequent analysis of correlating reading accuracy with degree of semantic impairment, however, we included only one observation for each patient, which was the first for the three patients tested longitudinally.

\section{Results}

\subsection{Accuracy}

Fig. 1 displays accuracy, averaged across the 14 sets of reading data, for each of the six conditions. A repeated measures ANOVA with frequency ( 2 levels) and word-type or consistency (3 levels) as within-participant factors yields significant main effects of both variables (frequency: $F(1,13)=108.52, p<0.001$; consistency: $F(2$, $26)=58.77, p<0.001$ ) plus a significant interaction between the two factors $F(2,26)=15.73, p<0.001)$.

Table 5 provides percent correct values in each condition for each individual patient, followed by mean values for each condition. For comparison, the table also gives means for the younger normal Japanese readers who, when tested on this same set of kanji words, achieved essentially perfect reading accuracy for all conditions except the low-frequency atypical kanji words, and even 96\% correct in this hardest condition (Fushimi et al., 1999). For patients whose reading accuracy is sensitive to a kanji word's consistency, performance on this set of words should follow the pattern consistent $\geq$ typical $\geq$ atypical. Of the 28 opportunities to test this prediction ( 2 frequency bands $\times 14$ sets of reading data), 24 of the 28 match this prediction. The only exceptions, where a patient's success on words in the next 'harder' condition was slightly (never more than $10 \%$ ) better than its preceding mate, were for SK-2 (high-frequency typical > consistent), ST (high-frequency atypical > typical), MO (ditto) and ST (low-frequency atypical > typical). Pearson's chi-squared statistic to test the outcome of 24/28 patterns matching the prediction against what would be expected if consistency were not determining the patients' reading performance yields $\chi_{(1)}^{2}=49.9, p<0.001$.

\subsection{Errors}

The appropriate level of detail with which one classifies errors in a task like oral reading depends on the research question for which the experiment was designed. The core question here, with regard to errors as well as accuracy, concerns the patients' sensitivity to the consistency of the component characters in the kanji words. Accordingly, the main error type of interest is the LARC: legitimate alternative reading of components, in which the reader assigns a pronunciation to a kanji character that is wrong for the target word but legitimate for that character in other words of which it is a component. Such responses have often been called 'regularisation errors' in the literature on disorders of reading, but were termed LARC errors (by Patterson et al., 1995) in an attempt to capture the fact that the $\mathrm{O} \rightarrow \mathrm{P}$ relationship in quasi-regular systems like English and Japanese kanji is graded rather than a regular/irregular dichotomy.

Fig. 2 displays, across the six word-type conditions, the average numbers of three different response types: correct, LARC and other errors. The important finding is that, even for higher-frequency words but especially for lower-frequency items, the number of LARC errors rose as consistency fell. In the higher-frequency band, LARC errors to atypical words already yielded about one-third of the quantity of correct responses; and in the lower-frequency band, LARC errors outnumbered correct responses to atypical words. There were a significant number of non-LARC errors, mainly consisting of responses that were either visually or phonologically similar to the target; and unsurprisingly there were more such 'other' errors to lower- than to higher-frequency items; but the rate of 'other' errors did not vary as a function of consistency as the LARC errors did. It should be noted, in case this seems puzzling, that LARC errors to consistent words, though very rare (see Fig. 2), are possible despite the definition of consistent words as those whose characters have no alternative pronunciations. The precise definition is no alternative pronunciation of such characters occurring in the same position. If that character can take an alternative pronunciation when it appears in a different position in a kanji word, and a patient assigned it this other pronunciation, it was classified here as a LARC error.

\subsection{Relationship between degree of semantic impairment and reading}

The hypothesis guiding this research predicts not only (a) that success in reading of kanji words by SD patients should relate to the words' consistency, but also (b) that this sensitivity to consistency should relate to degree of semantic impairment. Results from the three patients in the current series whose reading was assessed at several times points over $2-5$ years support this prediction to some degree. For example, TMO's success in reading consistent words was maintained well from testing round 1-2 (the latter occurring

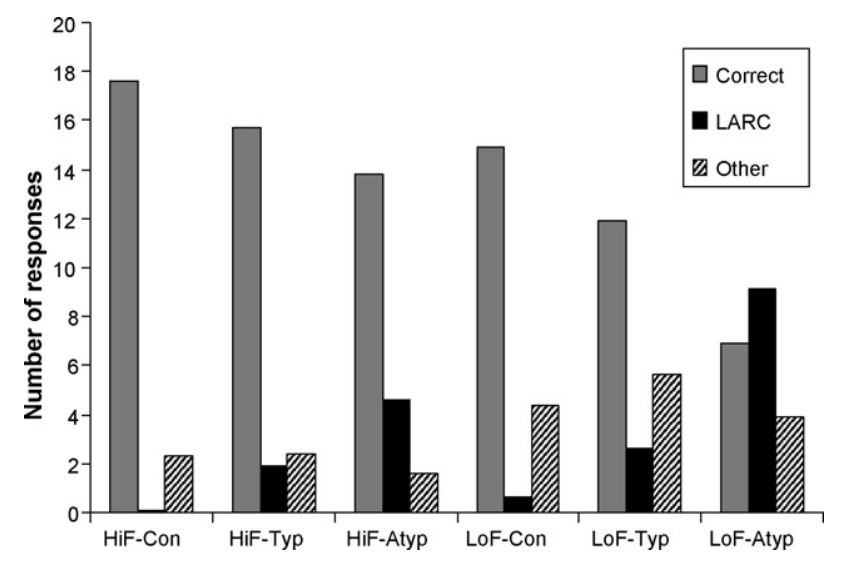

Fig. 2. Average number of three different types of reading response (correct, LARC error, other error) for each of the six conditions across the 14 sets of patient reading data. 
Table 5

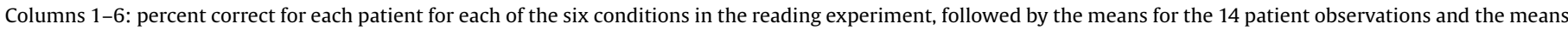

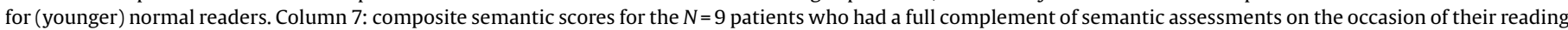
test.

\begin{tabular}{|c|c|c|c|c|c|c|c|}
\hline & Hi-freq. consistent & Hi-freq. typical & Hi-freq. atypical & Lo-freq. consistent & Lo-freq. typical & Lo-freq. atypical & Composite sem. score \\
\hline TI-1 & 90.0 & 85.0 & 65.0 & 85.0 & 70.0 & 30.0 & -0.42 \\
\hline TI-2 & 90.0 & 65.0 & 55.0 & 50.0 & 45.0 & 10.0 & \\
\hline TI-3 & 65.0 & 60.0 & 40.0 & 55.0 & 35.0 & 15.0 & \\
\hline SK-1 & 90.0 & 85.0 & 85.0 & 65.0 & 60.0 & 45.0 & 1.23 \\
\hline SK-2 & 75.0 & 85.0 & 60.0 & 65.0 & 40.0 & 35.0 & \\
\hline TMO-1 & 95.0 & 95.0 & 90.0 & 95.0 & 80.0 & 35.0 & 0.39 \\
\hline TMO-2 & 95.0 & 80.0 & 50.0 & 90.0 & 65.0 & 20.0 & \\
\hline YI & 85.0 & 85.0 & 70.0 & 65.0 & 50.0 & 30.0 & 0.81 \\
\hline TAM & 100.0 & 95.0 & 90.0 & 90.0 & 90.0 & 50.0 & 1.13 \\
\hline $\mathrm{MN}$ & 100.0 & 90.0 & 80.0 & 80.0 & 70.0 & 45.0 & 0.03 \\
\hline ST & 85.0 & 55.0 & 60.0 & 55.0 & 25.0 & 35.0 & 0.26 \\
\hline MO & 85.0 & 75.0 & 85.0 & 75.0 & 65.0 & 40.0 & -0.81 \\
\hline $\mathrm{CHN}$ & 100.0 & 90.0 & 90.0 & 100.0 & 85.0 & 70.0 & \\
\hline MT & 75.0 & 55.0 & 45.0 & 75.0 & 50.0 & 25.0 & -2.04 \\
\hline Patient mean & 87.9 & 78.6 & 68.9 & 74.6 & 59.3 & 34.6 & \\
\hline Control mean & 100.0 & 100.0 & 99.0 & 100.0 & 99.0 & 96.0 & \\
\hline
\end{tabular}

2 years after the former): round 1-2: 95-95\% for high frequency consistent words; round 1-2: 95-90\% for low frequency consistent words (see Table 5). By contrast, his scores on both inconsistenttypical and inconsistent atypical words decreased notably over the same time period.

For a more formal assessment of this prediction, we computed a composite semantic score for each patient $(N=9)$ who had a complete set of semantic tests in the same round on which he or she completed the reading test. This technique, employed in several previous studies (see for example Jefferies \& Lambon Ralph, 2006), uses a principal components analysis to obtain a weighted average of all available semantic scores. The scores contributing to this composite in the current study were all of the measures in Table 3 (in which we had already deliberately included only tests that tap semantic memory and only those not involving written words, so as to avoid any influence of reading ability) plus the three semantic tasks in Table 2 (category fluency, naming and spoken word-picture matching) which again do not involve written words. The composite scores appear in the final column of Table 5 . This set of $N=9$ composite semantic scores was entered into a correlation with the same 9 patients' reading scores for the three word-type conditions collapsed across frequency. The correlation yielded the following results: consistent: $r=0.24, p=0.53$, ns; typical: $r=0.42, p=0.26$, ns; atypical: $r=0.68, p=0.04)$. The correlation between composite semantic score and reading performance is significantly higher for atypical words than for consistent words, $t=1.98, N=9$, $p$ (onetailed) $=0.05$. The correlation for inconsistent-typical words, which is intermediate between those for consistent and atypical, does not differ significantly from either.

A graphical representation of the impact of degree of semantic deficit on reading of the three word classes is provided by Fig. 3, in which semantic composite scores have been grouped into three bands: mild: the three patients with the highest, or least impaired, semantic composite scores; moderate: the three patients in the middle of the range; severe: the three cases with the lowest, or most abnormal, semantic composite scores. Accuracy in reading of kanji words whose component characters have consistent pronunciations across their neighbourhoods was essentially immune to degree of semantic impairment. By contrast, accuracy in reading inconsistent typical words, and especially atypical words, declined in step with level of semantic deficit.

\section{General discussion}

Ten native Japanese-speaking/reading patients with SD, including three tested longitudinally over a period of several years, provided 14 data sets on reading aloud kanji words with varying degrees of consistency in the relationship between orthography and phonology. The study was governed by the hypothesis, already supported by case-series analyses in English-speaking/reading SD patients (Patterson et al., 2006; Wilson et al., in press; Woollams et al., 2007), that SD patients should exhibit surface dyslexia in oral reading. The basis for this hypothesis is the proposal that, in the normal system, semantic representations are activated in the oral reading process, even for single words; and further, that the additional activation of phonology by semantics $(S \rightarrow P)$ contributes significantly to correct pronunciation, especially of words with an atypical $\mathrm{O} \rightarrow \mathrm{P}$ relationship that do not receive overwhelming support for the correct pronunciation from the $\mathrm{O} \rightarrow \mathrm{P}$ process on its own (Dilkina et al., 2008; Plaut et al., 1996; Woollams et al., 2007). The obvious consequence of this hypothesis, developed in studies of reading in English by Patterson and Hodges (1992), Plaut et al. (1996), Patterson et al. (2006), and Woollams et al. (2007), is that the observed pattern of reading in patients with a central semantic deficit should be surface dyslexia.

This hypothesis, of course, applies to reading in any language/writing system, and an association between semantic dementia and surface dyslexia has been reported in languages other than English, including Dutch (Diesfeldt, 1992) and Italian (LauroGrotto, Piccini, \& Shallice, 1997; Rozzini, Bianchetti, Lussignoli, Cappa, \& Trabucchi, 1997). As explained in Section 1, the precise

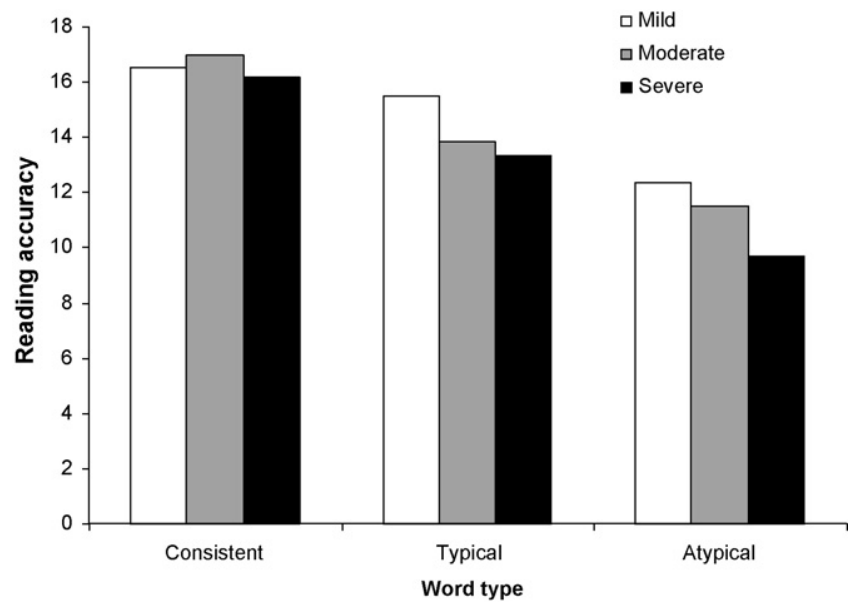

Fig. 3. Reading accuracy for the three word types as related to level of semantic impairment, with the patients grouped into three bands: mild, moderate and severe semantic deficit. 
predictions for a given language depend upon the characteristics of $\mathrm{O} \rightarrow \mathrm{P}$ typicality for the vocabulary of that language. Japanese constitutes an especially rich vehicle for exploring this relationship because its two dramatically different writing systems of kanji and kana occupy such different positions on the continuum of $\mathrm{O} \rightarrow \mathrm{P}$ typicality. The hypothesis that success in reading a word is jointly determined by (a) its $\mathrm{O} \rightarrow \mathrm{P}$ typicality, (b) its familiarity and (c) the reader's knowledge of its meaning leads to the following predictions for reading by Japanese SD patients: intact reading of kana and an impairment in kanji reading that is modulated by both frequency and consistency. Furthermore, if knowledge of a word's meaning is instrumental in computing the correct pronunciations of these lower-frequency atypical words, the degree of deficit on such words should be related to the level of semantic impairment, and errors on such words should mainly consist of legitimate alternative reading of components.

Previously published data regarding Japanese SD patients, though compatible with these predictions, were limited to four cases: one patient studied by Patterson et al. (1995) which involved a less sophisticated manipulation of kanji $\mathrm{O} \rightarrow \mathrm{P}$ consistency than the materials used here; two patients published by Nakamura et al. (2000), but only in Japanese; and one case studied by Fushimi et al. (2003) using the same materials employed here and extended in the current study to 10 patients and 14 testing rounds.

The results of the current investigation support all of the predictions. Kana reading was not investigated in any detail, but that is partly because there is little interest in establishing yet again that Japanese SD patients have flawless oral reading of kana characters and words, which they do (Fushimi et al., 2003; Patterson et al., 1995). All of the patients were impaired at reading kanji words and showed the expected consistency by frequency interaction. The patients' most common errors were LARC responses, which increased in number/proportion of responses as consistency of the items declined; 'other' errors, though certainly present in the patients' reading, did not vary in rate as a function of word consistency. Level of semantic impairment, estimated by a composite semantic score consisting of a number of different semantic tests using pictures or spoken words/sentences (but never written words), correlated significantly with the patients' performance in reading inconsistent-atypical words, correlated not at all with their success in reading consistent words, and correlated to an intermediate (though not statistically reliable) degree with inconsistent-typical items.

Our hypothesis that a degraded semantic system is responsible for SD patients' deficit in oral reading of lower-familiarity $\mathrm{O} \rightarrow \mathrm{P}$ atypical words is not the only way to explain the current results. One alternative that is similar but not identical to ours can be found in the context of the computational model of semantics and reading implemented by Dilkina et al. (2008). This account, somewhat like the one proposed by Plaut et al. (1996) and Woollams et al. (2007) on which the current work was based, eschews a separate lexical level of representation: reading is accomplished with a combination of (a) specialised but general (i.e., not word-specific) knowledge about $\mathrm{O} \rightarrow \mathrm{P}$ relationships, learned from the model's reading vocabulary, and (b) information supplied by a combined lexical-and-semantic integrative layer that also supports tasks like object naming. The main difference germane to this discussion is that, instead of proposing that the SD patients' impairment on a 'lexical' task like reading is caused by their central semantic deficit, the model of Dilkina et al. (2008) treats lexical and semantic knowledge as one system.

Another alternative that is more discrepant from our proposal views the central semantic deficit of SD as irrelevant to the one which causes surface dyslexia, namely a frequency-modulated impairment to lexical representations (Coltheart, 2006; Coltheart et al., 2001). This account (a) emphasises the SD cases in which a dissociation has been reported between semantic impairment and success in reading lower-frequency atypical words (two single cases: Blazely et al., 2005; Cipolotti \& Warrington, 1995); and (b) explains the more than 100 reported observations of an association between semantic degradation and impaired reading of lower-frequency atypical words as the result of chance anatomical contiguity between lexical and semantic representations. Patterson et al. (2006) argued against the latter interpretation on several grounds, including the fact that the semantic deterioration in SD disrupts performance on a number of tasks apart from reading (some verbal, some nonverbal; some receptive, some expressive) in precisely the same fashion: incorrect processing of lower-familiarity atypical items, with errors reflecting the typicality structure of the domain. In other words, this alternative interpretation may simply entail too many different lesion sites co-occurring by chance to be plausible.

Recent research on semantic dementia and surface dyslexia in English-speaking patients (especially Woollams et al., 2007) suggests that-although the degree of semantic degradation at which surface dyslexia emerges may vary from one patient to another-it is a case of when, not whether. The meaningfulness and theoretical implications of this association have been greatly strengthened by case-series designs, revealing that, with a combination of sensitive test materials and longitudinal testing, semantic impairment of the type characteristic of semantic dementia inevitably yields surface dyslexia. The extension of this finding to the largest case series of Japanese-speaking SD patients ever tested further enhances the meaningfulness of this association.

\section{Acknowledgements}

We are extremely grateful to Akie Saito, Satoru Saito and Taiji Ueno, of Kyoto University, for significant help with the data analysis from this study.

\section{References}

Adlam, A-L. R., Patterson, K., Rogers, T. T., Nestor, P., Salmond, C. H., Acosta-Cabronero, J., et al. (2006). Semantic dementia and fluent primary progressive aphasia: Two sides of the same coin? Brain, 129, 3066-3080.

Blazely, A. M., Coltheart, M., \& Casey, B. J. (2005). Semantic impairment with and without surface dyslexia: Implications for models of reading. Cognitive Neuropsychology, 22, 695-717.

Bozeat, S., Lambon Ralph, M. A., Patterson, K., Garrard, P., \& Hodges, J. R. (2000) Nonverbal semantic impairment in semantic dementia. Neuropsychologia, 38 , 1207-1215.

Cipolotti, L., \& Warrington, E. K. (1995). Semantic memory and reading abilities: A case report. Journal of the International Neuropsychological Society, 1, 104-110.

Coltheart, M. (2006). Acquired dyslexias and the computational modelling of reading. Cognitive Neuropsychology, 23, 96-109.

Coltheart, M., Rastle, K., Perry, C., Langdon, R., \& Ziegler, J. (2001). DRC: A dual route cascaded model of visual word recognition and reading aloud. Psychological Review, 108, 204-256.

Diesfeldt, H. F. A. (1992). Impaired and preserved semantic memory functions in dementia. In L. Backman (Ed.), Memory functioning in dementia. Amsterdam: Elsevier.

Dilkina, K., McClelland, J. L., \& Plaut, D. C. (2008). A single-system account of semantic and lexical deficits in five semantic dementia patients. Cognitive Neuropsychology, 25, 136-164.

Fushimi, T., Ijuin, M., Patterson, K., \& Tatsumi, I. F. (1999). Consistency, frequency, and lexicality effects in naming Japanese Kanji. Journal of Experimental Psychology: Human Perception and Performance, 25, 382-407.

Fushimi, T., Komori, K., Ikeda, M., Patterson, K., Ijuin, M., \& Tanabe, H. (2003). Surface dyslexia in a Japanese patient with semantic dementia: Evidence for similaritybased orthography-to-phonology translation. Neuropsychologia, 41, 1644-1658.

Hodges, J. R., \& Patterson, K. (1996). Nonfluent progressive aphasia and semantic dementia: A comparative neuropsychological study. Journal of the International Neuropsychological Society, 2, 511-524.

Hodges, J. R., Patterson, K., Oxbury, S., \& Funnell, E. (1992). Semantic dementia: progressive fluent aphasia with temporal lobe atrophy. Brain, 115, 1783-1806.

Jefferies, E., \& Lambon Ralph, M. A. (2006). Semantic impairment in stroke aphasia vs. semantic dementia: A case-series comparison. Brain, 129, 2132-2147.

Lambon Ralph, M. A., \& Howard, D. (2000). Gogi aphasia or semantic dementia? Assessing poor verbal comprehension in a case of fluent progressive aphasia. Cognitive Neuropsychology, 17, 437-466. 
Lambon Ralph, M. A., McClelland, J. L., Patterson, K., Galton, C. J., \& Hodges, J. R. (2001). No right to speak? The relationship between object naming and semantic impairment: Neuropsychological evidence and a computational model. Journal of Cognitive Neuroscience, 13, 341-356.

Lauro-Grotto, R., Piccini, C., \& Shallice, T. (1997). Modality-specific operations in semantic dementia. Cortex, 33, 593-622.

Marshall, J. C., \& Newcombe, F. (1973). Patterns of paralexia: a psycholinguistic approach. Journal of Psycholinguistic Research, 2, 175-199.

Nakamura, H., Nakanishi, M., Hamanaka, T., Nakaaki, S., \& Yoshida, S. (2000). Surface dyslexia and visual word recognition in Japanese. Higher Brain Function Research, 20, 136-144 [in Japanese with an English abstract].

Neary, D., Snowden, J. S., Gustafson, L., Passant, U., Stuss, D., Black, S., et al. (1998). Frontotemporal lobar degeneration: A consensus on clinical diagnostic criteria. Neurology, 51, 1546-1554.

Nishio, M., Iwabuchi, E., \& Mizutani, S. (1986). Iwanami Japanese dictionary (4th ed.). Tokyo: Iwanami Shoten. [in Japanese].

Patterson, K., \& Hodges, J. R. (1992). Deterioration of word-meaning: Implications for reading. Neuropsychologia, 30, 1025-1040.

Patterson, K., Lambon Ralph, M. A., Jefferies, E., Woollams, A., Jones, R., Hodges, J. R., et al. (2006). 'Pre-semantic' cognition in semantic dementia: Six deficits in search of an explanation. Journal of Cognitive Neuroscience, 18, 169183.

Patterson, K., Suzuki, T., Wydell, T., \& Sasanuma, S. (1995). Progressive aphasia and surface alexia in Japanese. Neurocase, 1, 155-165.
Plaut, D. C., McClelland, J. L., Seidenberg, M. S., \& Patterson, K. (1996). Understanding normal and impaired word reading: Computational principles in quasi-regular domains. Psychological Review, 103, 56-115.

Rozzini, L., Bianchetti, A., Lussignoli, G., Cappa, S., \& Trabucchi, M. (1997). Surface dyslexia in an Italian patient with semantic dementia. Neurocase, 3, 307-312.

Shallice, T., Warrington, E. K., \& McCarthy, R. (1983). Reading without semantics. Quarterly Journal of Experimental Psychology, 35A, 111-138.

SLTA Committee. (1997). Standard language test of aphasia manual. Tokyo: Shinkou Igaku Shuppan-sha. [in Japanese].

Snowden, J. S., Goulding, P. J., \& Neary, D. (1989). Semantic dementia: A form of circumscribed cerebral atrophy. Behavioural Neurology, 2, 111-138.

Snowden, J. S., Neary, D., \& Mann, D. M. A. (1996). Fronto-temporal lobar degeneration. New York: Churchill Livingstone.

Warrington, E. K. (1975). The selective impairment of semantic memory. Quarterly Journal of Experimental Psychology, 27, 635-657.

Wilson, S. M., Brambati, S. M., Henry, R. G., Handwerker, D. A., Miller, B. L., Wilkins, D. P., Ogar, J. M., \& Gorno-Tempini, M. L. (in press). The neural basis of surface dyslexia in semantic dementia. Brain. Access on November 20,2008, doi:10.1093/ brain/awn300.

Woollams, A. M., Cooper-Pye, E., Hodges, J. R., \& Patterson, K. (2008). Anomia: A doubly typical signature of semantic dementia. Neuropsychologia, 46, 2503-2514.

Woollams, A. M., Lambon Ralph, M. A., Plaut, D. C., \& Patterson, K. (2007). SDsquared: On the association between semantic dementia and surface dyslexia. Psychological Review, 114, 316-339. 